\title{
COMPARISON OF POLYJET PRINTING AND SILICON MOULDING AS RAPID PLASTIC MOULDING SOLUTIONS
}

\author{
R. Singh \\ Faculty of Production Engineering, Guru Nanak Dev Engg. College, Ludhiana-141006, \\ India Phone: +9198722 57575, Fax: +91 1612502700. \\ E-mail: rupindersingh78@yahoo.com
}

\begin{abstract}
The aim of the present investigation is to compare two rapid molding (RM) solutions, namely polyjet printing (PP) and silicon molding (SM), for the manufacture of plastic components. The comparison has been made on the basis of dimensional accuracy (as per IT grades), mechanical properties (namely surface hardness, surface roughness) and production cost. The comparison of the experimental results will serve as a yard stick for the further selection of processes for industrial applications.
\end{abstract}

Keywords: Plastic components; rapid molding; dimensional accuracy; hardness.

\section{INTRODUCTION}

Rapid prototyping (RPT) has been in evidence for the past twenty years, and due to its impressive growth various techniques (like stereo lithography, selective laser sintering (SLS), polyjet printing (PP), silicon molding (SM), etc.) and machines have been developed (Singh, 2010a). Wohlers (1995) highlighted the fact that with the use of this technology, astounding reductions in design and prototyping cycles can be obtained, as well as measurable improvements in the new product quality. PP, based on ink jet technology under U.S. patent no. US005340656, and SM are considered to be two of the most future-oriented rapid prototyping (RP) systems available for plastic components (Ainsworth et al., 2000; Sachs et al., 1994; Singh and Singh, 2009a; Singh and Verma, 2008). Figures 1 and 2 show schematics of the PP and SM processes, respectively. These RP techniques are extending their fields of application, far beyond the original idea of generating design iterations (Singh and Singh, 2010). The applications have been extended from the building of aesthetic and functional prototypes to the production of tools and molds for technological prototypes (Singh and Verma, 2008). Layer by layer construction applied to tool and die making, directly from virtual designs (from computer aided design or from animation modeling software), is defined as rapid tooling (RT) (Bernard et al., 2003; Chua and Leong, 2000). Manufacturers are increasingly looking towards RT, especially for short production runs that do not justify the investment required for conventional hard tooling (Ainsworth et al., 2000; Rooks, 2002; Singh, 2010b; Song et al., 2001). A variety of tools can currently be produced using different RP technologies. For the purpose of classification, tooling is divided into direct or indirect tooling (Chua and Leong, 2000). In direct tooling, the tool or die is created directly by the RP process. In the indirect tooling, which is used in the present research work, only the master is created using RP technology. From this master a mold is made out of a material such as silicon rubber, epoxy resin, soft metal, or ceramic. Most rapid tooling methods today are indirect. RP parts are used as patterns for making molds and dies. Patterns, cores and cavities for metal castings can be obtained through 
these rapid casting (RC) techniques (Bernard et al., 2003; Rooks, 2002; Song et al., 2001).

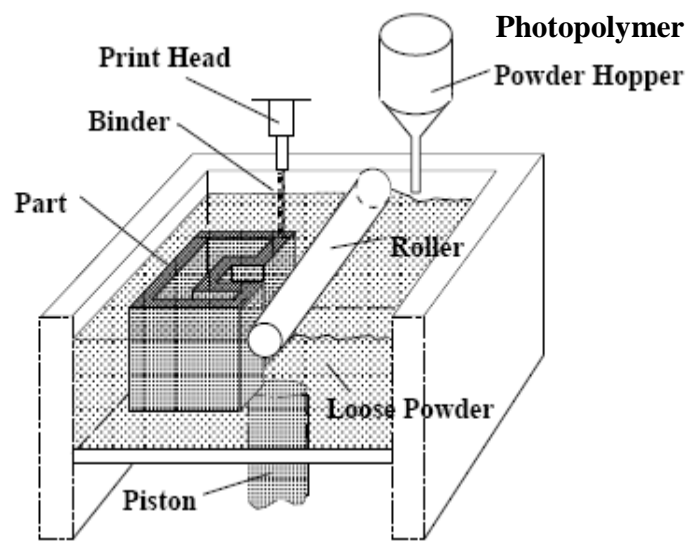

Figure 1. PP process (Singh and Verma, 2008)

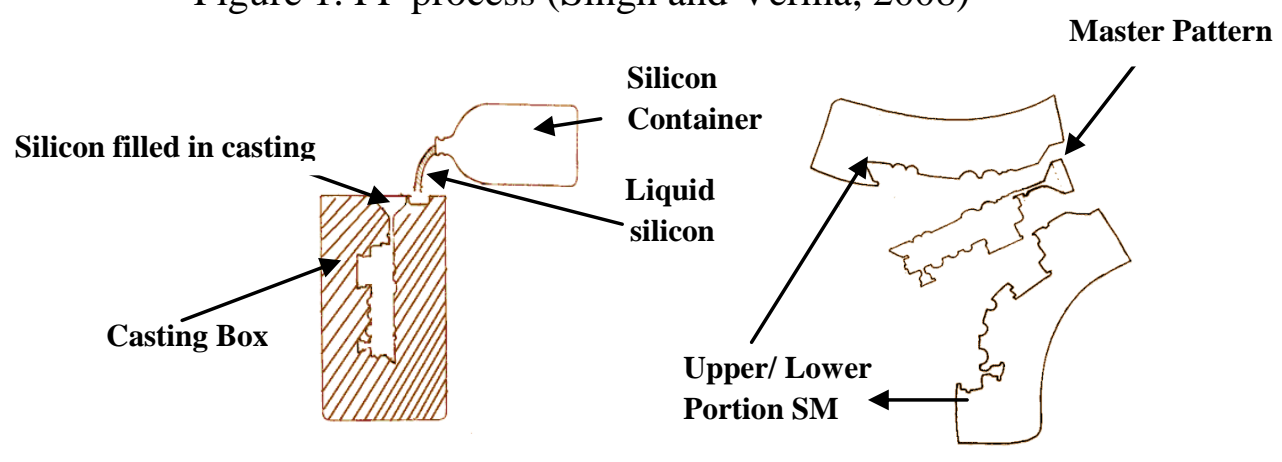

Figure 2. SM process (Singh, 2010b)

By using RPT techniques (PP and SM) to produce the ceramic shells with integral cores directly from the CAD model, a number of the disadvantages of the traditional molding process are avoided (Singh, 2010b). Most significant is that the metal dies are typically expensive and time consuming to produce, with lead times ranging from two to six months (Singh and Singh, 2009b). For relatively small and complex parts, the benefits of additive manufacturing can be significant (Bak, 2003; Ramos et al., 2003). In this field, innovative solutions are now available based on PP and SM processes, which can extend RM possibilities thanks to the lower costs with respect to previous technologies such as SLS. Components can be made by depositing a preliminary layer of powder material in a confined region and then depositing a binder material onto selected regions of the layers of the powder material to produce a layer of bonded powder material in previously selected regions. Such steps are repeated a determined number of times to produce successive layers of selected regions of bonded powder material in order to form the desired component. The unbounded powder material is then removed. Bassoli et al. (2006) conducted studies on technological solutions based upon PP and investment casting. This study was aimed at evaluating the dimensional accuracy of two RC solutions in the production of cavities for light-alloy castings. Some researchers also proposed similar studies with regard to different 
solutions for the production of technological prototypes (Ramos et al., 2003; Wang et al., 1999). The present research aims at using the PP and SM technology as a RM solution for plastic components. A 'RP' shell model was used as the positive pattern. An effort has been made, through experimentation, to compare two RM solutions namely PP and SM for plastic components. The comparison has been made on the basis of dimensional accuracy (as per IT grades), mechanical properties (namely surface hardness, surface roughness) and production cost. The comparison of experimental results will serve as yard stick for the future selection of processes for industrial applications. The consistency of the tolerance grades (IT grades) of the RM solutions obtained are as per the permitted ISO standards. Experimental studies regarding this solution are lacking in the literature, in particular the technological feasibility of thinwalled parts needs to be assessed and the dimensional tolerances calculated.

\section{EXPERIMENTATION}

For the present study, a plastic component was chosen as a benchmark, representative of the manufacturing field, where the applications of the RM technologies are particularly relevant. The component selected for the present study is a pen drive cover. The experimental procedure started with the 2-D modeling of the benchmark (see Figure 3). To obtain the best settings of the PP machine in terms of layer thickness, part orientation and post curing time, the upper and lower shell prototypes were produced using a RM solution based on PP and SM (see Figure 4). Plastic components manufactured with PP (poly jet, model EDN260 object) are of photopolymer material (namely: full cure 720, vero white, vero blue) and for post curing UV rays were used during the process. Further components manufactured with SM are resin (polyurethane) based. A number of experiments were conducted for the possible outcomes of the PP and SM processes, with the objective of minimizing the production costs and improving the dimensional as well as mechanical properties. Figure 5 shows a rapid mold prepared by the SM process. Starting from the CAD model, components were prepared with two different grades of resin/polyurethane (namely: Alchemix VC3340 and Alchemix VC3360). From an analysis of the geometry and volume of the benchmark, a single feeder and riser system was designed for pouring the molten plastic. RP shell models are used as positive patterns around which the resin was filled in a molding box. Based upon pilot experimentation (see Table 1) vero white material in the horizontal position has been selected for PP. The measurement paths for the internal and the external surfaces of the benchmark have been generated through measurement software of the DEA Iota 0101 CMM (Ainsworth et al., 2000). The dimension measured with CMM is the outer component length. The outer diameter was measured from the mean diameter of ten (10) circles at different points. The curve radius was measured by scanning the inner and outer curve surfaces (Kaplas and Singh, 2008). The results of the dimensional measurements have been used to evaluate the tolerance unit (n), starting from the standard tolerance factor i, defined in ISO standard UNI EN 20286-1 (Italian National Standards Body, 1995). The values of standard tolerances corresponding to IT5-IT18 grades, for nominal sizes up to $500 \mathrm{~mm}$, are evaluated by considering the standard tolerance factor $\mathrm{i}$ (in micrometers) indicated by the following formula, where $D$ is the geometric mean of the range of nominal sizes in millimeters.

$$
\text { Tolerance factor } i=0.45(D){ }^{1 / 3}+0.001 D
$$


In fact, the standard tolerances are not evaluated separately for each nominal size, but for a range of nominal sizes. For a generic nominal dimension $D_{\mathrm{JN}}$, the number of the tolerance units ' $n$ ' is evaluated as follows:

$$
n=1000\left(D_{J N}-D_{J M}\right) / i
$$

where $D_{J M}$ is a measured dimension.
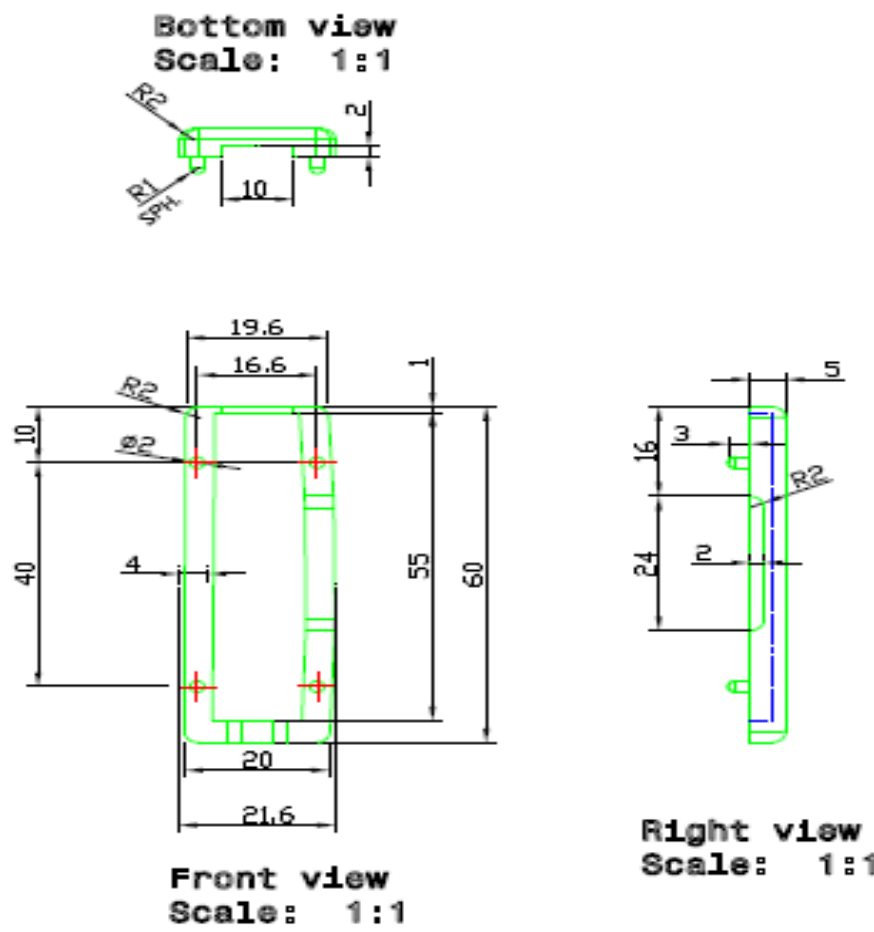

Scale: 1:1
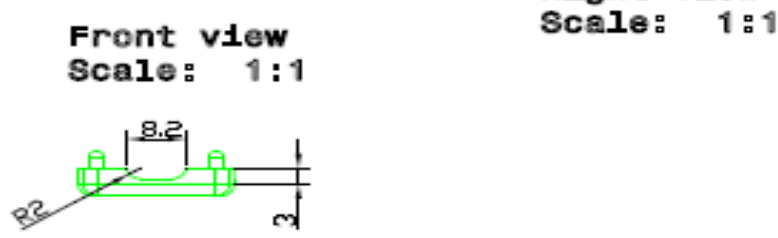

Figure 3. 2-D model of the benchmark
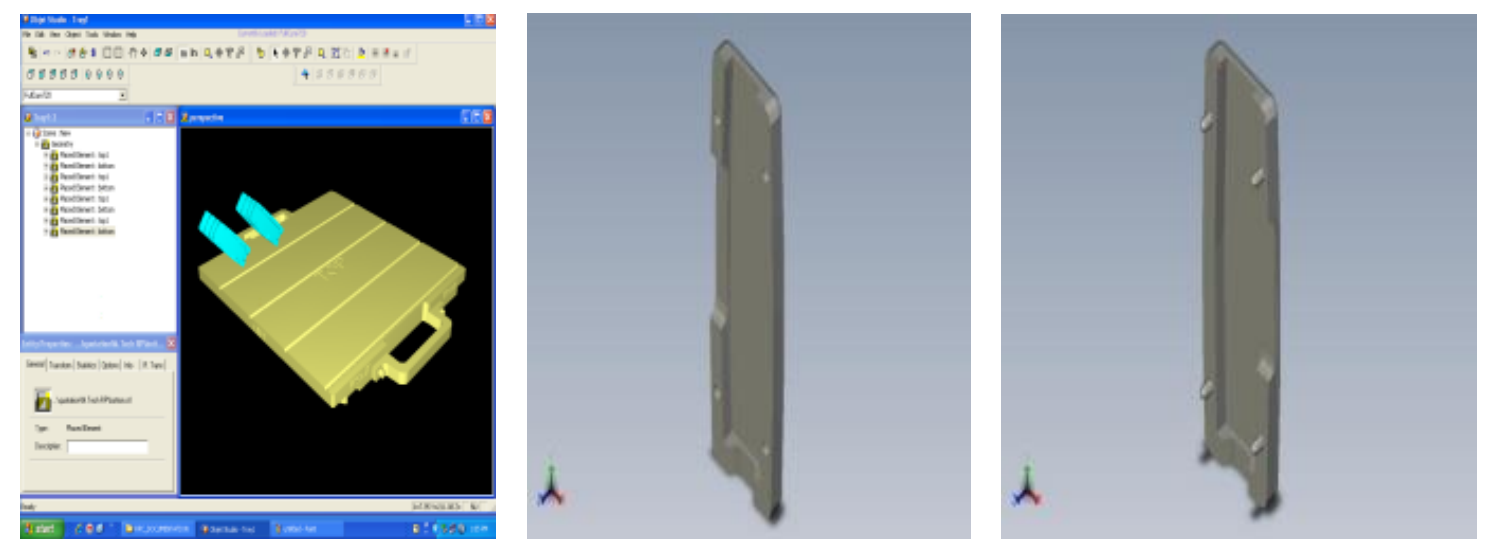

Figure 4. CAD model of the benchmark 


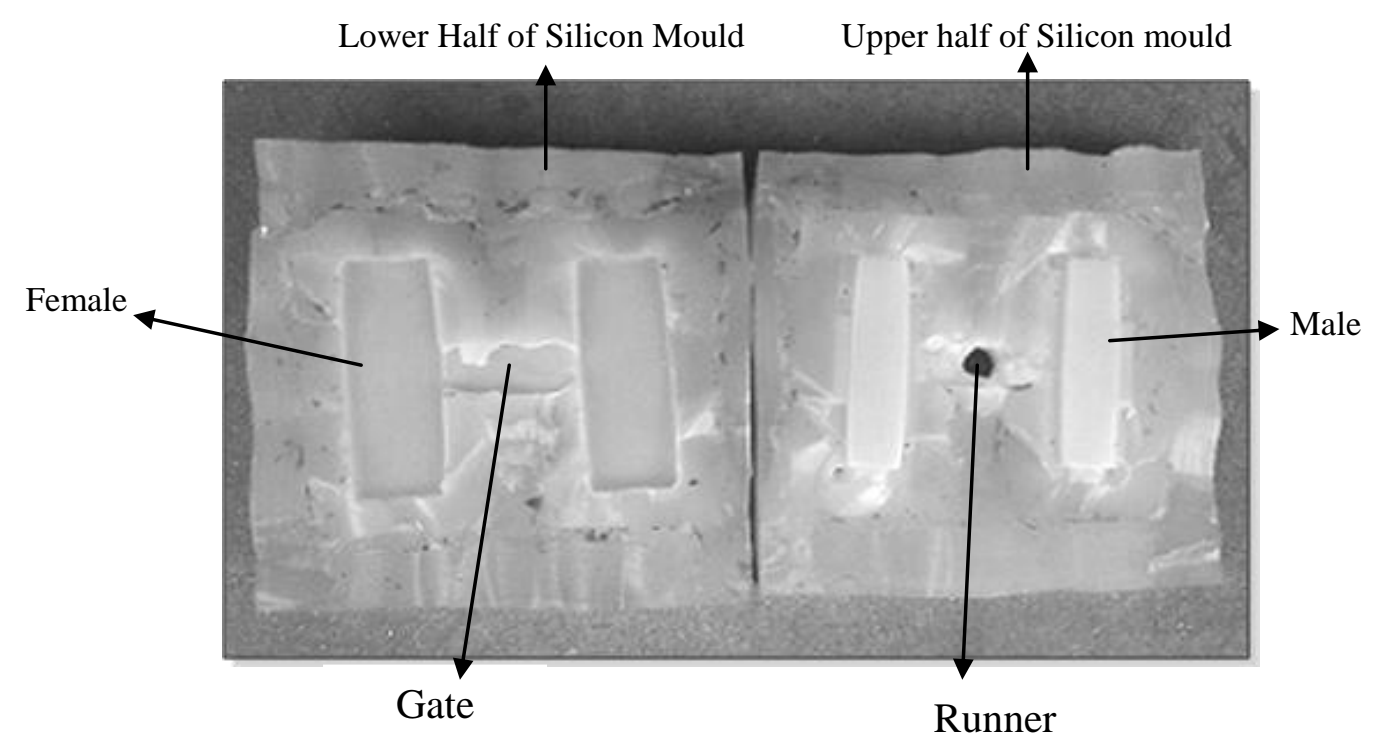

Figure5. Rapid mold prepared by SM process

Table 1. Observations of pilot experiments on PP

\begin{tabular}{llcc}
\hline Plastic material & Orientation & Nominal dimension & Measured dimension \\
\hline Full cure 720 & Horizontal & 60 & 59.8908 \\
Full cure 720 & Vertical & 60 & 60.1294 \\
Full cure 720 & At 45 & 60 & 59.4320 \\
Vero white & Horizontal & 60 & 59.8909 \\
Vero white & Vertical & 60 & 59.8342 \\
Vero white & At 45 & 60 & 59.5342 \\
Vero blue & Horizontal & 60 & 59.6866 \\
Vero blue & Vertical & 60 & 59.8122 \\
Vero blue & At $45^{\circ}$ & 60 & 59.4121 \\
\hline
\end{tabular}

The tolerance is expressed as a multiple of $\mathrm{i}$ : for example, IT14 corresponds to $400 \mathrm{i}$ with $n=400$. The results of the dimensional measurements are used to evaluate the tolerance grades. The obtained tolerance grades are IT 14 and IT 15 (Lewis et al, 2001). It is important to note that the tolerance grades calculated for the considered RC techniques are consistent with the values allowed for casting operations, between IT11 and IT18 (Kaplas and Singh, 2008). The technological prototypes are thus completely acceptable for all plastic materials, but better dimensional accuracy is obtained with the vero white material (see Table 2). Similarly, IT grades for plastic components produced by SM were evaluated, which are in the range IT11-IT12. Surface roughness $(R a)$ values in the cases of PP and SM based plastic components are around 0.64 and 0.52 $\mu \mathrm{m}$ respectively. Furthermore, it has been observed that the hardness of the components produced is almost same with both processes. Table 3 shows a comparison of the 3DP and SM processes. On the basis of cost considerations, the cost per piece of components produced by PP is around 6US\$, however for the SM process the cost for a single component is around 15US\$. 
Table 2. IT grades according to UNI EN 20286-I (Italian National Standards Body, $1995)$ for PP based plastic components $(i=1.8192)$ in horizontal orientation

\begin{tabular}{lclcc}
\hline Plastic material & D JN $_{\text {JN }}$ & D $_{\text {JM }}$ & n & IT Grade \\
\hline Full cure 720 & 60 & 59.8908 & 198 & IT12 \\
Full cure 720 & 60 & 59.8828 & 213 & IT12 \\
Full cure 720 & 60 & 59.8762 & 225 & IT12 \\
Vero white & 60 & 59.9209 & 143 & IT11 \\
Vero white & 60 & 59.9122 & 159 & IT11 \\
Vero white & 60 & 59.9342 & 119 & IT10 \\
Vero blue & 60 & 59.8866 & 206 & IT11 \\
Vero blue & 60 & 59.8952 & 190 & IT11 \\
Vero blue & 60 & 59.8873 & 205 & IT12 \\
\hline
\end{tabular}

Table3. Comparison of 3DP and SM processes

\begin{tabular}{ll}
\hline \multicolumn{1}{c}{ 3DP process } & \multicolumn{1}{c}{ SM process } \\
\hline Tolerance grade IT10-12 & Tolerance grade IT11-12 \\
Ra Value: $0.64 \mu \mathrm{m}$ & Ra value: $0.52 \mu \mathrm{m}$ \\
Batch production cost: High & Batch production cost: Low \\
Hardness: $68 \mathrm{HRB}$ & Hardness: $62 \mathrm{HRB}$ \\
\hline
\end{tabular}

It should be noted that a PP based mold cannot be reused, whereas a SM based mold can be used for around 100 pieces (Singh, 2010b). For batch production of 100 plastic components the cost will be:

Using PP the cost will be: $100 \times 6=600$ US $\$$

Using SM the cost will be: $100 \times(2.4)^{*}+15=255$ US $\$$

$*$ (2.4US\$ is additional cost of resin used per piece)

Hence for a batch production of 100 pieces with SM there is significant reduction in production cost.

\section{CONCLUSIONS}

The PP and SM techniques provided satisfactory results for plastic components. With respect to traditional molding, this process ensures the rapid production of pre-series technological prototypes. On the basis of experimental observations made on the plastic moldings, the following conclusions can be drawn:

1. It is feasible to reproduce plastic components with PP and SM processes. The tolerance grades of the components produced are consistent with the permissible range of tolerance grades (IT grades) as per the ISO standard UNI EN 20286-I (Italian National Standards Body, 1995).

2. The dimensional accuracy, surface finish and hardness obtained with PP and SM processes are within a similar range. However for job shop production PP is a better process over SM, whereas for batch production SM is better.

3. The adopted procedure is better for developing proof of concept and for new products, for which the cost of production of the dies and other tooling is greater. The results are in line with the experimental observations made by other investigators. 


\section{REFERENCES}

Ainsworth, I., Ristic, M. and Brujic, D. 2000. CAD-based measurement path planning for free form shapes using contact probes. International Journal of Advanced Manufacturing Technology, 16(1): 23-31.

Bak, D. 2003. Rapid prototyping or rapid production? 3D printing processes move industry towards the latter. Rapid Prototyping Journal, 23(4): 340-345.

Bassoli, E., Gatto, A., Iuliano L. and Violante, M.G. 2006. 3D printing technique applied to rapid casting. Rapid Prototyping Journal, 13(3): 148-155.

Bernard, A., Delplace, C.J., Perry, N. and Gabriel, S. 2003. Integration of CAD and rapid manufacturing for sand casting optimization. Rapid Prototyping Journal, 5: 327-333.

Chua, C.K. and Leong, K.F. 2000. Rapid prototyping: principles and applications in manufacturing. 1st ed., Chapter 6. New York: John Wiley and Sons.

Italian National Standards Body. 1995. UNI EN 20286-1: ISO system of limits and fits. Bases of tolerances, deviations and fits. UNI.

Kaplas, M. and Singh, R. 2008. Experimental investigations for reducing wall thickness in zinc shell casting using three dimensional printing. Proceedings of IMechE Part C, Journal of Mechanical Engineering Sciences, 222(C12): 2427-2431.

Lewis, R.W., Manzari, M.T. and Gethin, D.T. 2001. Thermal optimisation in the sand casting process. Engineering Computations, 3(4): 392-416.

Ramos, A.M., Relvas, C. and Simoes, J.A. 2003. Vacuum casting with room temperature vulcanising rubber and aluminium moulds for rapid manufacturing of quality parts: a comparative study. Rapid Prototyping Journal, 9(2): 111-115.

Rooks, B. 2002 Rapid tooling for casting prototypes. Rapid Prototyping Journal, 22(1): 40-45.

Sachs, E.M., Haggerty, J.S., Cima, M.J. and Wiliams, A.P. 1994. Three dimensional printing techniques. US Patent No. US 005340656.

Singh, J.P. and Singh, R. 2009a. Comparison of rapid casting solutions for lead and alloys using three dimensional printing. Proceedings of IMechE Part C, Journal of Mechanical Engineering Sciences, 223(C9): 2117-2123.

Singh, J.P. and Singh, R. 2009b. Investigations for statistically controlled rapid casting solution of lead alloys using three dimensional printing. Proceedings of IMechE Part C, Journal of Mechanical Engineering Sciences, 223(C9): 2125-2134.

Singh, J.P. and Singh, R. 2010. Comparison of statistically controlled rapid casting solutions of brass alloys using three dimensional printing. International Journal of Manufacturing Technology and Industrial Engineering, 1(1): 67-77.

Singh, R. 2010a. Three dimensional printing for casting applications: a state of art review and future perspectives. Advanced Material Research, 83-86: 342-349.

Singh, R. and Verma, M. 2008. Investigations for reducing wall thickness of aluminium shell casting using three dimensional printing. Journal of Achievements in Materials and Manufacturing Engineering, 31(2): 565-569.

Singh, B. (2010b) Process capability of silicon moulding process for plastic components. Master Thesis, P.T.U. Jalandhar, India.

Song, Y., Yan, Y., Zhang, R., Lu, Q. and Xu, D. 2001. Three dimensional non-linear coupled thermo-mechanical FEM analysis of the dimensional accuracy for casting dies in rapid tooling. Finite Elements in Analysis and Design, 38: 79-91. 
Wang, W., Conley, J.G. and Stoll, H.W. 1999. Rapid tooling for sand casting using laminated object manufacturing process. Rapid Prototyping Journal, 5(3): 134140.

Wohlers, T. 1995. Future potential of rapid prototyping and manufacturing around the world. Rapid Prototyping Journal, 1(1): 4-10. 